\title{
Review \\ The Role of Membrane Lipids in Light-Activation of Drosophila TRP Channels
}

\author{
Rita Gutorov, Ben Katz, Elisheva Rhodes-Mordov, Rachel Zaguri, Tal Brandwine-Shemmer and Baruch Minke *
}

check for

updates

Citation: Gutorov, R.; Katz, B.;

Rhodes-Mordov, E.; Zaguri, R.; Brandwine-Shemmer, T.; Minke, B. The Role of Membrane Lipids in Light-Activation of Drosophila TRP Channels. Biomolecules 2022, 12, 382. https://doi.org/10.3390/ biom12030382

Academic Editors: Klaus Groschner and Christoph Romanin

Received: 31 January 2022

Accepted: 23 February 2022

Published: 28 February 2022

Publisher's Note: MDPI stays neutral with regard to jurisdictional claims in published maps and institutional affiliations.

Copyright: (C) 2022 by the authors. Licensee MDPI, Basel, Switzerland. This article is an open access article distributed under the terms and conditions of the Creative Commons Attribution (CC BY) license (https:// creativecommons.org/licenses/by/ $4.0 /)$.
Department of Medical Neurobiology, Institute for Medical Research Israel-Canada (IMRIC), Faculty of Medicine and Edmond and Lily Safra Center for Brain Sciences (ELSC), The Hebrew University, Jerusalem 91120, Israel; rita.gutorov@mail.huji.ac.il (R.G.); ben.katz@mail.huji.ac.il (B.K.); elisheva.rhodes@mail.huji.ac.il (E.R.-M.); rachel.segura@mail.huji.ac.il (R.Z.); tal.brandwine@mail.huji.ac.il (T.B.-S.)

* Correspondence: baruch.minke@mail.huji.ac.il

\begin{abstract}
Transient Receptor Potential (TRP) channels constitute a large superfamily of polymodal channel proteins with diverse roles in many physiological and sensory systems that function both as ionotropic and metabotropic receptors. From the early days of TRP channel discovery, membrane lipids were suggested to play a fundamental role in channel activation and regulation. A prominent example is the Drosophila TRP and TRP-like (TRPL) channels, which are predominantly expressed in the visual system of Drosophila. Light activation of the TRP and TRPL channels, the founding members of the TRP channel superfamily, requires activation of phospholipase C $\beta$ (PLC), which hydrolyzes phosphatidylinositol 4,5-bisphosphate $\left(\mathrm{PIP}_{2}\right)$ into Diacylglycerol (DAG) and Inositol 1, 4,5trisphosphate $\left(\mathrm{IP}_{3}\right)$. However, the events required for channel gating downstream of PLC activation are still under debate and led to several hypotheses regarding the mechanisms by which lipids gate the channels. Despite many efforts, compelling evidence of the involvement of DAG accumulation, PIP $_{2}$ depletion or $\mathrm{IP}_{3}$-mediated $\mathrm{Ca}^{2+}$ release in light activation of the TRP/TRPL channels are still lacking. Exogeneous application of poly unsaturated fatty acids (PUFAs), a product of DAG hydrolysis was demonstrated as an efficient way to activate the Drosophila TRP/TRPL channels. However, compelling evidence for the involvement of PUFAs in physiological light-activation of the TRP/TRPL channels is still lacking. Light-induced mechanical force generation was measured in photoreceptor cells prior to channel opening. This mechanical force depends on PLC activity, suggesting that the enzymatic activity of PLC converting $\mathrm{PIP}_{2}$ into DAG generates membrane tension, leading to mechanical gating of the channels. In this review, we will present the roles of membrane lipids in light activation of Drosophila TRP channels and present the many advantages of this model system in the exploration of TRP channel activation under physiological conditions.
\end{abstract}

Keywords: Drosophila TRP channel; TRPL channel; phospholipase C $\beta$; Diacylglycerol (DAG); Diacylglycerol kinase (DGK); poly unsaturated fatty acids (PUFAs); methyl- $\beta$-cyclodextrin; cholesterol; ergosterol

\section{Introduction}

The Transient Receptor Potential (TRP) superfamily, which is conserved through evolution, consists of seven subfamilies (TRPC, TRPV, TRPM, TRPA, TRPN, TRPML, and TRPP) and its members are expressed in many cell types, including excitable as well as nonexcitable cells [1]. These channels participate in many sensory modalities (e.g., vision, taste, temperature, pain, and pheromone detection) and they either open directly in response to ligands or physical stimuli (e.g., temperature, osmotic pressure) or open indirectly, downstream of receptor activation (e.g., Rhodopsin, Histamine, and Bradykinin [2,3]) and the inositol-lipid signaling cascade. In addition to the wide variety of activation mechanisms, the activity of TRP channels is modulated by numerous factors, including the lipid environment in which the channel is embedded, posttranslational modifications 
such as phosphorylation, nitrosylation and glycosylation, ligand biding such as $\mathrm{Ca}^{2+}$ and ATP and by interaction of the channels with different binding partners [4]. Despite many efforts over the years, the gating mechanism of the founding members of the TRP channel superfamily, the Drosophila TRP and TRP-like (TRPL) channels is still elusive.

Visual systems of animals are characterized by high sensitivity to light and this property is obtained by a high expression level of the signaling components within the retinal cells. The retina of Drosophila is an excellent example of this principle as revealed by expression of huge amounts of signaling components and by achieving the ultimate sensitivity to light-single photon detection. Drosophila utilizes the phosphoinositide cascade for phototransduction with TRP channels as its target $[2,3]$. Hence, the Drosophila retina is a unique tissue with regard to TRP channels, as most tissues do not express high amounts of TRP channels. This TRP-enriched tissue enables robust biochemical analysis combined with the power of the Drosophila molecular genetics and the accuracy of light activation and constitutes a valuable preparation for investigating the complex mechanism of TRP channel gating under physiological conditions. Despite having many advantages, the Drosophila photoreceptor preparation still has several limitations, including the polarity of the Drosophila photoreceptor cells and the dense membrane of the signaling compartment (rhabdomere), which limits pipette accessibility to the channels, making it difficult to directly determine the single channel properties under physiological conditions ([5], but see below).

Lipid regulation of channels is mostly thought as ligand-protein interaction with a defined binding site at the channel surface. However, recent in-silico lipid docking analysis using solved channel structures suggests that some lipid binding sites enable binding of multiple lipid "poses" [6]. Another interesting theory developed for the gating mechanism of Drosophila TRP/TRPL channels proposed that the TRP/TRPL channels are mechanically gated. Accordingly, the measured force generated by changes in membrane lipid packing and the generation of membrane tension during the enzymatic activity of PLC and the conversion of $\mathrm{PIP}_{2}$ into DAG, gate the mechanical sensitive TRP/TRPL channels. This theory emphasizes that the lipid environment in which the channels are embedded is crucial for their performance.

In the present review we summarize the evidence supporting the involvement of lipids in light-activation of the TRP/TRPL channels. Moreover, we will discuss conflicting and missing data required for elucidating the mechanism underlying lipid-activation of the TRP/TRPL channels.

\section{The Involvement of the Inositol-Lipid Signaling in TRP Channel Activation}

One of the most important contributions of the Drosophila retinal preparation to the study of TRP channels in general and of the TRPC channels subfamily in particular is the discovery that Gq-mediated phospholipase C $\beta$ (PLC) has an essential role in physiological activation of the TRP channels (Figure 1). Evidence for possible participation of PLC in Drosophila phototransduction arose from initial biochemical studies, showing that highly reduced PLC enzymatic activity was found in the no receptor potential A (norpA) mutants [7-9]. Further detailed functional evidence for a light-dependent $\mathrm{G}_{\mathrm{q}} \alpha$-mediated PLC activity in fly photoreceptors came from combined biochemical and electrophysiological experiments. These experiments revealed coupling of photoexcited rhodopsin to phosphatidylinositol 4,5-bisphosphate $\left(\mathrm{PIP}_{2}\right)$ hydrolysis [10]. Furthermore, using temperaturesensitive norp $A$ mutant allele [11], correlation between light-activated $\mathrm{PIP}_{2}$ hydrolysis and the electrical response to light was demonstrated [12]. The findings of the biochemical and electrophysiological studies were strongly supported by a genetic study, resulting in the isolation and analysis of the Drosophila gene, norp $A$, which was found to encode a $\beta$-class PLC, predominately expressed in the rhabdomeres and has high amino acid homology to a PLC extracted from bovine brains [13]. The norpA mutant thus provides essential evidence for the critical role of PLC and the inositol-lipid signaling in fly phototransduction, by 
showing that no light excitation takes place in the absence of a functional PLC. However, the events required for light excitation downstream of PLC activation remain unresolved.
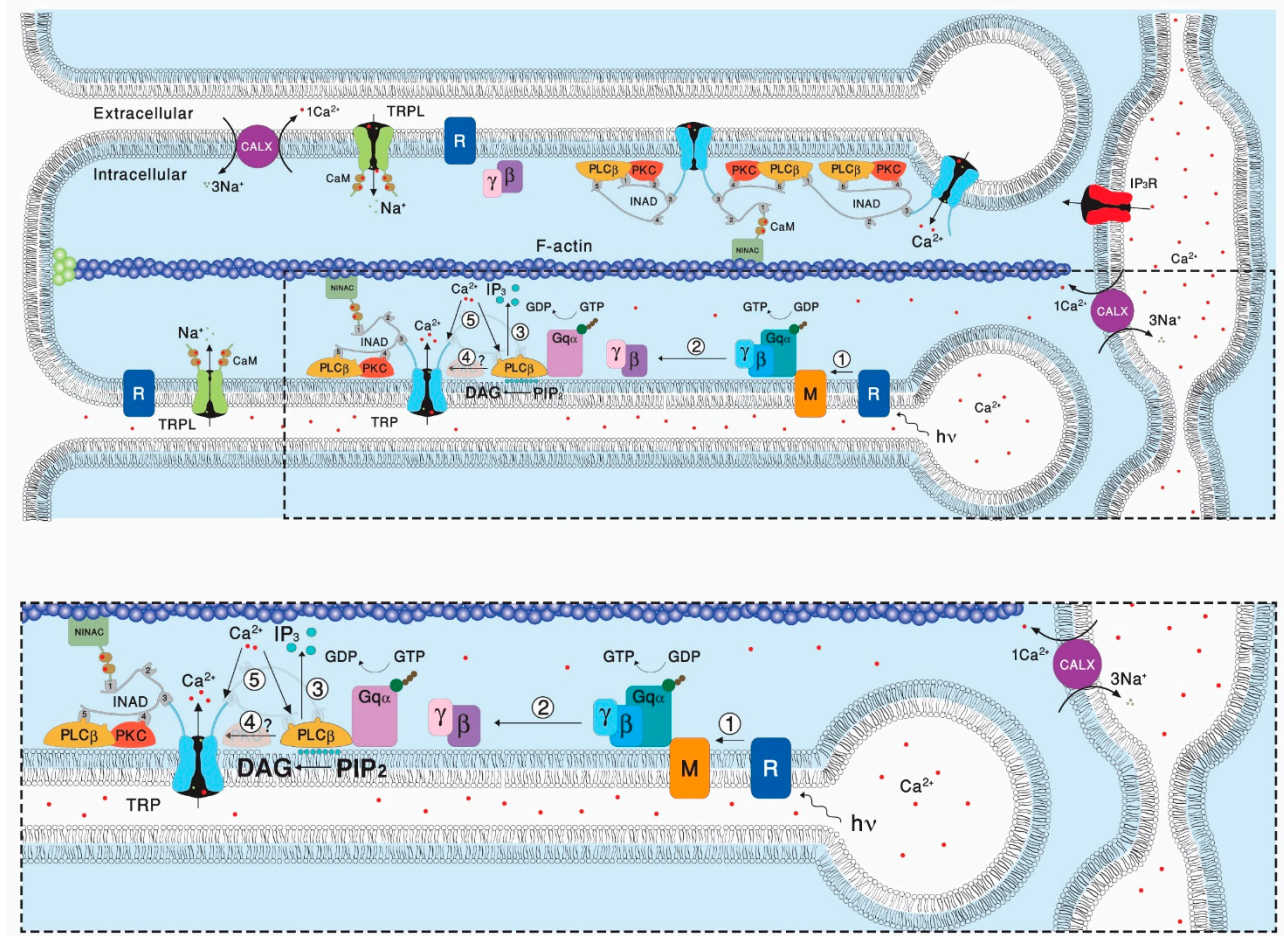

Figure 1. The phosphoinositide cascade of vision. A diagram showing the molecular components of the signal transduction cascade of Drosophila: 1. Upon absorption of a photon (hv), rhodopsin $(\mathrm{R})$ is converted into metarhodopsin (M). 2. The R to M photoconversion leads to the activation of heterotrimeric $\mathrm{G}$ protein $(\mathrm{Gq} \alpha \beta \gamma)$ by promoting the GDP to GTP exchange. 3. The GTP-bound Gq $\alpha$, in turn leads to activation of phospholipase $\mathrm{C} \beta$ (PLC $\beta$ ), which hydrolyzes $\mathrm{PIP}_{2}$ into the soluble $\mathrm{IP}_{3}$ and the membrane bound DAG. 4. PLC $\beta$ in a still unclear way activates the TRP and TRPL channel, leading to an increase in microvillar $\mathrm{Ca}^{2+}$ concentration. 5. The increased $\mathrm{Ca}^{2+}$ concentration feeds back and negatively regulate both PLC and TRP channels activities. Elevation of DAG and $\mathrm{Ca}^{2+}$ promotes eye-specific protein kinase C (PKC) activity, which regulates channel activity. PLC $\beta$, PKC, and the TRP ion channel form a supramolecular complex with the scaffolding protein INAD, which is bound to the F-actin cytoskeleton via the NINAC protein. $\mathrm{Ca}^{2+}$ level in the microvilli is also regulated by the $\mathrm{Na}^{+}-\mathrm{Ca}^{2+}$ exchanger, CALX. The diagram at the bottom is an amplification of the box marked by dotted lines in the upper diagram. (Modified from [14]).

A reduction in the levels of PLC in mutant flies affect the amplitude and activation kinetics of the light response [15], but surprisingly also induce the slow response termination. This slow response termination of most norp $A$ mutant alleles had no explanation for many years. Later biochemical and physiological studies conducted in Drosophila revealed the requirement for PLC in GTPase-activating proteins (GAP) activity in vivo [16], suggesting that the PLC enzyme also acts as a GAP [17]. The virtually complete dependence of GAP activity on PLC provides an efficient mechanism for ensuring the one photon, one single photon response (quantum bump) relationship [18], which is critical for the fidelity of phototransduction at dim light [16]. PLC activity is known to be regulated by $\mathrm{Ca}^{2+}$ [19]. It has been shown that $\mathrm{Ca}^{2+}$ is bound to the catalytic site of PLC and is required as a co-factor for the catalytic reaction [20]. These studies showed that the positive charge of $\mathrm{Ca}^{2+}$ is used to counterbalance local negative charges formed in the active site during the course of the catalytic reaction. Accordingly, $\mathrm{Ca}^{2+}$ electrostatically stabilizes both the substrate and the transition state, thus providing a 2-fold contribution to lower the energy of the enzymatic reaction [21]. In Drosophila, both in vitro [22] and in vivo [23] measurements 
revealed $\mathrm{Ca}^{2+}$ dependence of PLC activity. This activity shows a bell-shaped dependence of PLC catalytic activity on $\mathrm{Ca}^{2+}$ concentration $\left(\left[\mathrm{Ca}^{2+}\right]\right)$, with maximal basal activity in the range of $10^{-7}-10^{-5} \mathrm{M}\left[\mathrm{Ca}^{2+}\right]$. This complex dependency affects both excitation and adaptation of the photoresponse. While at physiological conditions cellular $\mathrm{Ca}^{2+}$ levels are sufficient for the activation of PLC, it was demonstrated that highly reduced $\mathrm{Ca}^{2+}$ levels eliminated excitation completely [24]. Furthermore, it was shown that during the light response, rhabdomeric $\mathrm{Ca}^{2+}$ concentration can reach $\mathrm{mM}$ levels $[25,26]$. At this high $\mathrm{Ca}^{2+}$ level, PLC activity is attenuated, raising the possibility of physiological relevance [23]. Later studies have shown that the inhibition of PLC activity by high $\mathrm{Ca}^{2+}$ concentration participates in the mechanism of fast light adaptation and prevents depletion of membrane $\mathrm{PIP}_{2}$. Accordingly, the high $\mathrm{Ca}^{2+}$ concentration, reached at the peak response, attenuates PLC activity, preventing $\mathrm{PIP}_{2}$ depletion and adapting the cells by reducing excitation [27]. The transient response phenotype observed in trp mutants was explained by this same mechanism [28]. Accordingly, the reduced $\mathrm{Ca}^{2+}$ permeability in the trp mutant, results in reduced $\mathrm{Ca}^{2+}$ influx during illumination through the low $\mathrm{Ca}^{2+}$ permeable TRPL channels. This reduced $\mathrm{Ca}^{2+}$ influx becomes insufficient to attenuate PLC activity, thereby depleting the pool of $\mathrm{PIP}_{2}$ and causing the attenuation of the light response [28,29]. Indeed, the response to light of WT flies under low $\mathrm{Ca}^{2+}$ conditions also showed a trp phenotype [30,31]. The trp phenotype was also observed in null $r d g B$ mutants in which the PI-cycle (Figure 2) is defective and $\mathrm{PIP}_{2}$ depletion is expected after intense light illumination ([32], but see [33]). Initially, models of light-activated TRP/TRPL channels assumed that the $\mathrm{IP}_{3}$ branch of the inositol-lipid signaling leads to $\mathrm{IP}_{3}$-induced $\mathrm{Ca}^{2+}$ release from intracellular stores (Figure 1) mediating light-induced TRP/TRPL channels opening [34,35], whereby the released $\mathrm{Ca}^{2+}$ functions as a second messenger of excitation acting either in a store depletion mechanism (SOC, [36]) or as a receptor-activated channel (ROC, [37]). However, in Drosophila these mechanisms were not supported by experimental evidence [38-40] and therefore were abandoned and the lipid branch of PLC-dependent signaling was adopted [41,42]. Recently, a rapid light-induced release of $\mathrm{Ca}^{2+}$ from the ER by the $\mathrm{Na}^{+} / \mathrm{Ca}^{2+}$ exchanger (CALX, [41]) was demonstrated (Figure 1). However, This CALX-dependent $\mathrm{Ca}^{2+}$ release was too slow to be involved in channel activation and there is no information on $\mathrm{ER} \mathrm{Na}^{+}$levels. Thus, the physiological role of this mechanism is still unknown. 


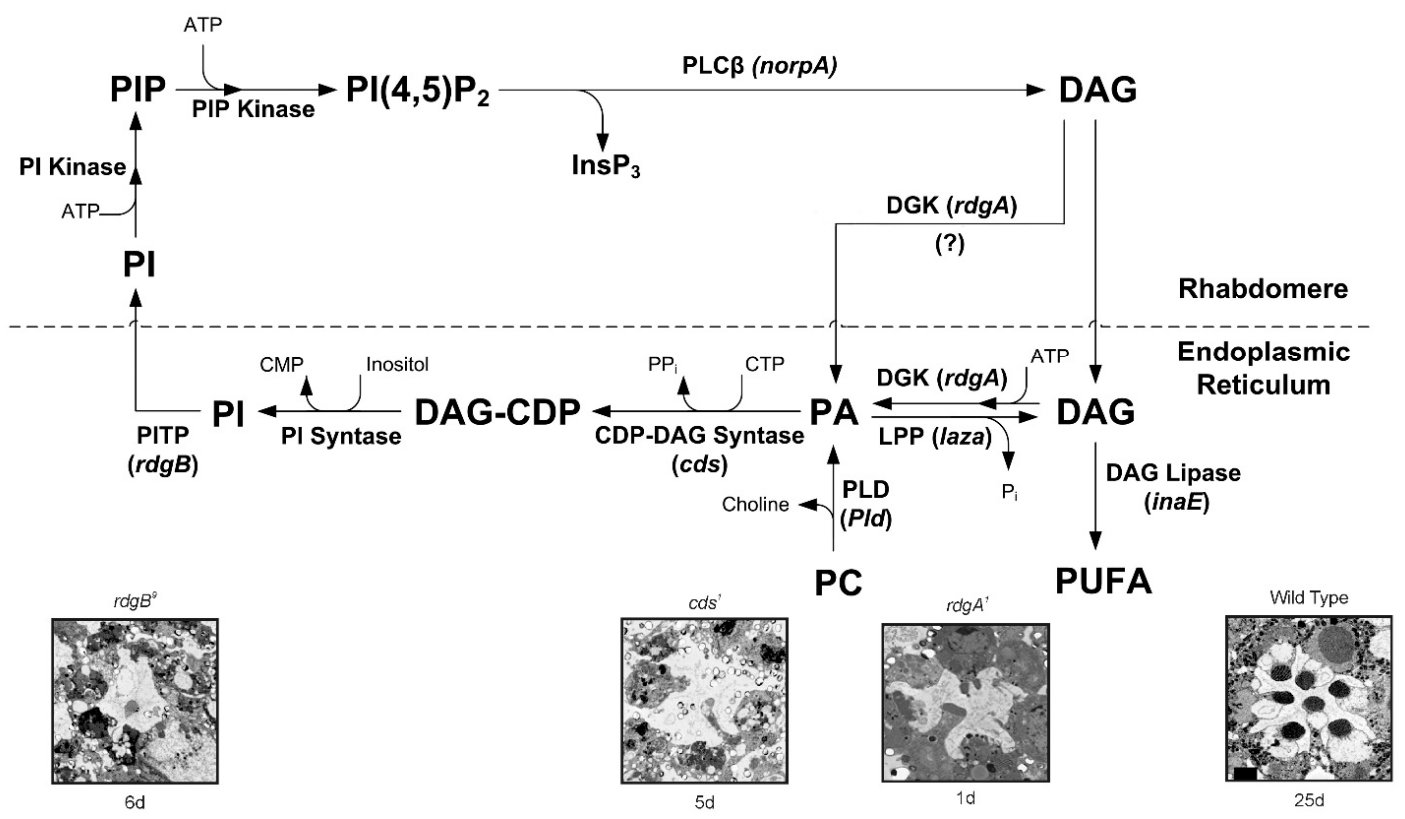

Figure 2. The phosphoinositide cycle in Drosophila photoreceptors. In the phototransduction cascade, light triggers the activation of PLC $\beta$. This catalyzes hydrolysis of the membrane $\mathrm{PIP}_{2}$ into watersoluble $\mathrm{InsP}_{3}$ and membrane-bound DAG. The continuous functionality of the photoreceptors during illumination is maintained by rapid regeneration of $\mathrm{PIP}_{2}$ in a cyclic enzymatic pathway (the PI cycle). DAG is transported by endocytosis to the endoplasmic reticulum (SMC) and inactivated by phosphorylation into PA via DGK. DGK may also be localized in the rhabdomeres. PA is converted to CDP-DAG via CDP-DAG syntase (encoded by the $c d s$ gene). PA can be converted back to DAG by lipid phosphate phosphohydrolase (LPP; also designated phosphatidic acid phosphatase (PAP) encoded by laza). PA is also produced from PC by PLD (encoded by Pld). DAG is hydrolyzed by DAG lipases, leading to the generation of PUFA. However, for PUFA generation, either an sn-2 DAG lipase or an additional enzyme (mono-acyl glycerol (MAG) lipase) would be required, but there is no evidence of either in Drosophila photoreceptors. Nevertheless, sn-1 type DAG lipase (encoded by inaE) was isolated. This DAG lipase was predominantly localized outside the rhabdomeres. The above difficulties put in question the participation of PUFA in channel activation in vivo. Subsequently, CDP-DAG is converted into phosphatidyl inositol (PI), which is transferred back to the microvillar membrane, by the PITP (encoded by the $r d g B$ gene). Both RDGA and RDGB proteins have been immunolocalized to the SMC at the base of the rhabdomere. PIP and $\mathrm{PIP}_{2}$ are produced at the microvillar membrane by PI kinase and PIP kinase, respectively. Bottom: The ultrastructure of highly degenerated ommatidia induced by three mutations in the genes $r d g B, c d s, r d g A$, which appear in the upper scheme: and wild type for a comparison. (Modified from [43]).

\section{Lipid Composition of the Drosophila Head/Retina and the Effects of Its Modification}

There is mounting evidence that lipids have profound effects on the activity of ion channels in general and on members of the TRPC subfamily in particular [44]. Lipids of Drosophila head membranes have been analyzed using thin layer chromatography, gas liquid chromatography $[45,46]$, and nano-electrospray ionization tandem mass spectrometry (ESIMS/MS) [47]. These studies revealed the presence of $\sim 50 \%$ phosphatidyl-ethanolamine (PE), 25\% phosphatidyl-choline (PC), and 12\% phosphatidyl-inositol (PI). Contrary to vertebrate photoreceptors, long chain polyunsaturated fatty acids (more than 18 carbons) were not detected in Drosophila phospholipids [46]. In addition to phospholipids, Drosophila head membranes contain sphingolipids and, instead of cholesterol, ergosterol [47,48]. The ergosterol content of Drosophila head membranes was determined by ESI-MS/MS and revealed $\sim 26 \mathrm{nmol}$ ergosterol per $\mathrm{mg}$ of membrane proteins [47]. The sphingolipids are composed of a tetradeca-4-sphingenine and a saturated fatty acid [48]. Since these studies 
used membranes of entire Drosophila heads, the obtained quantitative results may not mirror the exact lipid composition of photoreceptor membranes.

Lipidomic analysis of fly heads raised on a yeast-free diet showed that the lack of Poly Unsaturated Fatty Acids (PUFAs) in this diet was reflected in marked differences in fatty acids composition of all the major phospholipids in the heads. In particular, while monosaturated lipid species were little affected, polyunsaturated (with 3 or more double bonds) were greatly reduced in all classes of phospholipids. Interestingly $\mathrm{PIP}_{2}$, the PLC substrate in heads of flies reared on normal diet was in order of abundance 36:2 > 36:3 > 34:2 = 36:4 > 34:1 (carbon number: number of double bonds). In flies raised on the yeast-free diet, PUFAs of 36:4 and 36:3 were almost eliminated and 34:1 increased accordingly. The results obtained from fly heads were compared to results obtained from dissected retinae and a closely overlapping profile was observed [49]. To conclude, in flies reared on yeast-free diet lacking PUFAs, mass spectrometry showed that the proportion of polyunsaturated phospholipids was seven-fold reduced (from 38 to $5 \%$ ) but rescued by adding a single species PUFA to the diet. The yeast free diet caused a 2- to 3-fold increase in light response latency and time to peak, but had no effect on the waveform of the single photon responses (quantum bumps). Interestingly, in flies raised on yeast-free diet a reduction in light sensitivity of $\sim 10$-folds was observed in WT flies under low $\mathrm{Ca}^{2+}$ conditions and in trp mutant flies in which $\mathrm{Ca}^{2+}$ influx is reduced. It is important to note that this diet had virtually no effect on PLC activity [49]. The effect of the membrane phospholipids manipulation under a yeast-free diet is expected to change the stiffness and elasticity of the membrane. Hence, the authors suggested that a 2- to 3-fold increase in response latency, which appeared to be mediated downstream of PLC and was correlated with a slowing of the light-induced contractions in accordance with mechanical gating of the channels (see below).

\section{Evidence for Lipids Action as Second Messengers}

Many mammalian TRP channels can be characterized as ionotropic receptors since they can be activated directly under physiological conditions by physical stimuli such as heat, cold, mechanical, or by natural chemicals such as capsaicin, menthol, or mustard oil [50]. One of the key features of presumably all members of the TRPC subfamily is their indirect physiological activation via PLC $\beta$-mediated signal transduction cascades. Since PLC activity is essential for activation of the TRP/TRPL channels, recycling its substrate, $\mathrm{PIP}_{2}$, is essential for proper light response. PLC catalyzes hydrolysis of the membrane phospholipid $\mathrm{PIP}_{2}$ into water soluble $\mathrm{IP}_{3}$ and membrane-bound diacylglycerol (DAG, [51]). This enzymatic reaction is enhanced by illumination and initiates a cyclic enzymatic pathway called the PI cycle (Figure 2). Many enzymatic components of the complex PI cycle were discovered using genetic dissection by screening for mutations and utilizing the power of the Drosophila molecular genetics [52]. Following PLC activation, the phospholipid branch of the PI cycle begins by DAG transport through endocytosis to the endoplasmic reticulum designated submicrovillar cisternae (SMC, but see below). Subsequently, DAG is inactivated by phosphorylation and converted into phosphatidic acid (PA, [53,54] via DAG kinase (DGK), encoded by the retinal degeneration $\mathrm{A}(r d g A)$ gene that was discovered as a mutant causing rapid retinal degeneration in the dark [53,54]. Then, CDP-DAG synthase enzyme encoded by the $c d s$ gene [55] produces CDP-DAG from PA (Figure 2). Subsequently, CDP-DAG is converted into phosphatidylinositol (PI), which is transferred back to the microvillar membrane, by the PI transfer protein (PITP), encoded by the retinal degeneration B ( $r d g B$ gene [56]) located to the SMC. This mutant was discovered as a mutant causing rapid light-induced retinal degeneration [57-59]. PIP and $\mathrm{PIP}_{2}$ are produced at the microvillar membrane by PI kinase and PIP kinase, respectively. PA can be reconverted back to DAG by lipid phosphate phosphohydrolase, LPP, also designated phosphatidic acid phosphatase, PAP, encoded by the laza gene [60,61] or produced from phosphatidylcholine (PC) by phospholipase D (PLD), encoded by the pld gene [62,63]. Lightregulated PLD activity is required to maintain PA levels during illumination and support the maintenance of apical membrane (rhabdomere) size. Thus, PLD is a key regulator of 
plasma membrane turnover during receptor activation and signaling in photoreceptors [63], while the PA level is tightly regulated by phosphorylation-dephosphorylation enzymatic reactions carried out by the LPP phosphatase (laza), and DAG kinase ( $r d g A)$, both localized to the ER (Figure 2, but see below). PLD also works in coordination with retromer function and ADP-ribosylation factor 1 (Arf1) activity to regulate apical membrane size during illumination [63].

Mutations in several enzymes of the PI cycle result in retinal degeneration. For example, mutations in RDGA result in a light-independent retinal degeneration, while mutations in RDGB and CDS result in light-dependent degeneration (Figure 2). The mechanism underlying light-dependent degeneration of the $r d g B$ and $c d s$ mutants is unknown. However, for the lightindependent retinal degeneration of the $r d g A$ mutant flies, a mechanism for the degeneration was proposed. Accordingly, the degeneration occurs due to a sustained $\mathrm{Ca}^{2+}$ influx through the lightactivated TRP and TRPL channels. Since mutations affecting proteins of the PI cycle downstream to PLC activation lead to retinal degeneration due to toxic increasing cellular $\mathrm{Ca}^{2+}(r d g A$, [64]), or possibly due to $\mathrm{PIP}_{2}$ depletion [28], the PI cycle is relevant for understanding phototransduction and TRP channel activation. A detailed analysis of the rdgA mutant encoding DAG kinase established the importance of the DAG branch in channel activation. In addition to light independent retinal degeneration, this mutant shows constitutive activity of the light activated channels, while a partial rescue of the degeneration was observed, when $r d g A$ was crossed into a trp mutant background $\left(r d g A^{1} ; \operatorname{trp}{ }^{P 343},[64]\right)$. Furthermore, it has been shown that light response is partially rescued in hypomorphic mutant flies with severe reduction in light sensitivity, such as norp $A^{P 16}$ and $G_{q} \alpha^{1}$ on the background of $r d g A\left(\right.$ norp $A^{P 16}, r d g A^{1}$ and $\left.r d g A^{1} /+; G_{q} \alpha^{1}\right)$, while $\operatorname{rdg} A$ amplifies the light response, thus supporting the hypothesis that DAG is involved in channel activation [65]. This hypothesis is consistent with a recent observation reporting that the human TRPC5 channel exhibits a binding site for DAG near the pore region, commensurate with a key role of DAG for TRPC5 channel activation [66,67]. Omission of ATP from the whole-cell recording pipette combined with application of metabolic inhibitors activate the TRP and TRPL channels in the dark [68-70] (Figure 3). This dark activation of the channel [71] by metabolic inhibition [68] was effectively mimicked by the $r d g A$ mutation in DAG kinase (DGK, [64]), suggesting that ATP depletion mainly inhibits DGK activity. It furthermore suggests that DGK normally suppresses spontaneous dark activity of PLC-mediated production of DAG [70]. Indeed, a considerable spontaneous $\mathrm{Gq} \alpha$ activity inducing spontaneous PLC activity in the dark was observed in Drosophila photoreceptors [29,72]. Accordingly, relatively large currents were reversibly induced within only a few seconds of application of mitochondrial uncouplers (either $10 \mu \mathrm{M}$ CCCP or $0.1 \mathrm{mM}$ DNP) to WT Drosophila photoreceptors in recordings made soon after establishing the whole-cell configuration (Figure 3). The light-sensitive channels were invariably activated by DNP or CCCP either with or without ATP in the electrode, although activation was quicker and not indefinitely reversible when no ATP was included. However, when DNP or CCCP were applied after the spontaneous dark current was eliminated by strong Gq $\alpha$ or PLC hypomorph mutants, no current activation by metabolic inhibition was observed, indicating that the dark current induced by metabolic inhibition is generated by Gq $\alpha$-mediated PLC activity [70]. The most obvious interpretation of these results is that metabolic inhibition activates the TRP/TRPL channels via the same molecular mechanism by which light activates these channels, namely by generation of DAG that, in a still unclear manner, is involved in channel activation. Several lines of evidence challenge this hypothesis. (a) Application of DAG to intact ommatidia or to tissue culture cells expressing TRPL did not activate the channels (our unpublished data, Hardie personal communication), while application of DAG to TRPC3 channels expressed in these tissue culture cells did activate the TRPC3 channels serving as a positive control [73]. Nevertheless, application of DAG analogues 1-oleoyl-2-acetyl-snglycerol (OAG) at low concentration $(2 \mu \mathrm{M})$ to inside-out patches excised from the microvilli of dissociated Drosophila ommatidia resulted in activation of the TRP and TRPL [74,75]. However, channels activation was slower by 3 orders of magnitude ( 60 s after application, (Delgado and Bacigalupo, 2009)) compared to the ms fast light activation [29]. (b) Immuno-gold EM localization of DAG kinase (the $r d g A$ gene product) was confined to the smooth endoplasmic 
reticulum (SMC [54]), a relatively distant cellular compartment from the transduction machinery and this localization was consistent with detailed biochemical studies of the PI cycle using Drosophila mutants [52,63] making DGK localization inconsistent with controlling a second messenger level. However, a recent immunofluorescence localization showed that DGK is localized to the rhabdomeres [76], while biochemical assays revealed a light-induced increase of DAG in the Drosophila retina [74]. Thus, the role of DAG as a possible light-generated second messenger of excitation remains unresolved.

A

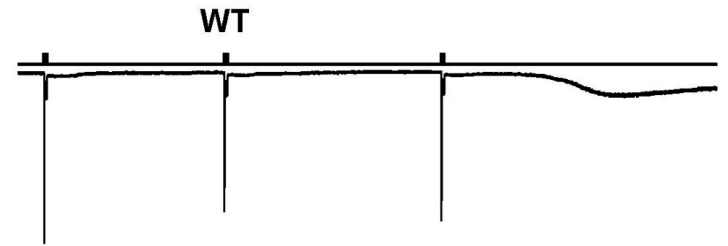

B

WT

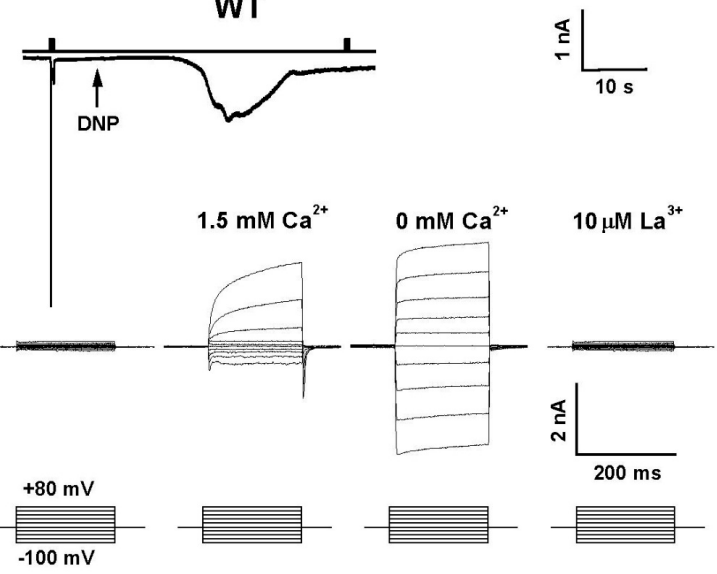

Figure 3. Depletion of cellular ATP activated the TRP channels: Membrane currents are usually elicited by light in the present of ATP and NAD in the pipette. Omission of these agents, combined with either few light pulses or with application of DNP to the bath induced constitutive activation of the light sensitive channels as monitored by a sustained noisy inward current that had the characteristics of the TRP or TRPL-dependent current. None of these currents were observed in the double null mutant $\operatorname{trpl}_{\text {; }}{ }^{P 343}$. (A) The typical light induced current (LIC) of a wild type (WT) cell in response to orange lights (Schott OG 590, attenuated by 1 log unit) in the absence of ATP and NAD in the pipette. Note that after 3 light-pulses the TRP channels open spontaneously (right). The light monitor is indicated above the measured current traces. (B) Membrane currents were recorded $30 \mathrm{~s}$ after establishing the whole-cell configuration with physiological concentrations (1.5 $\mathrm{mM})$ of $\mathrm{Ca}^{2+}$ in the bath. Whole cell recordings were conducted with pipettes, in which ATP and NAD were omitted and DNP was applied to the external medium at a time indicated by an arrow. Note the LIC was elicited by a light-pulse and the continuous opening of the channels in the dark following application of DNP. Also note that an additional light stimulus during the dark current elicited no response. (C): Families of current traces elicited by series of voltage steps from photoreceptors of wild type before (left traces) and following application of DNP (all other traces) in the presence of $1.5 \mathrm{mM} \mathrm{Ca}^{2+}$ in the bath (second family traces), with $\sim 0$ (nominal) $\mathrm{mM} \mathrm{Ca}^{2+}$ in the bath (third family traces) and when $10 \mu \mathrm{M} \mathrm{La}^{3+}$ was applied to the bath (fourth family traces). For each experiment, a series of nine voltage steps was applied from a holding potential of $-20 \mathrm{mV}$ in $20 \mathrm{mV}$ steps (bottom traces). (From [68], Copyright 2000 Society for Neuroscience).

\section{PUFAs Activation of TRP and TRPL Channels in the Dark}

One of the striking findings of Hardie and colleagues in studies of Drosophila photoreceptors was the demonstration that PUFAs such as linolenic or linoleic acid (LA) are potent activators of the TRP/TRPL channels in the dark. This robust, but still slower activation relative to light activation was demonstrated in both photoreceptor cells $[77,78]$ and in cultured S2 cells ([77,78], 
Figure 4) and HEK cells [73] heterologously expressing TRPL channels. Direct activation of the channels by PUFAs without the need for PLC was demonstrated by showing that PUFAs can activate blind Drosophila mutants virtually lacking $\mathrm{G}_{\mathrm{q}} \alpha[77]$ or PLC $[77,78]$ in a similar manner to activation of WT flies (Figure 5). In cultured S2 cells heterologously expressing TRPL channels, PUFA activation of the channels was not accompanied by $\mathrm{PIP}_{2}$ hydrolysis, as demonstrated by the lack of fluorescence translocation from the plasma membrane to the cytosol of GFP-PH $\mathrm{PLC} \delta 1_{1}$ domain. Activation of the muscarinic receptor, which is coupled to PLC induced fluorescence translocation to the cytosol, served as a positive control ([73], Figure 5).

A

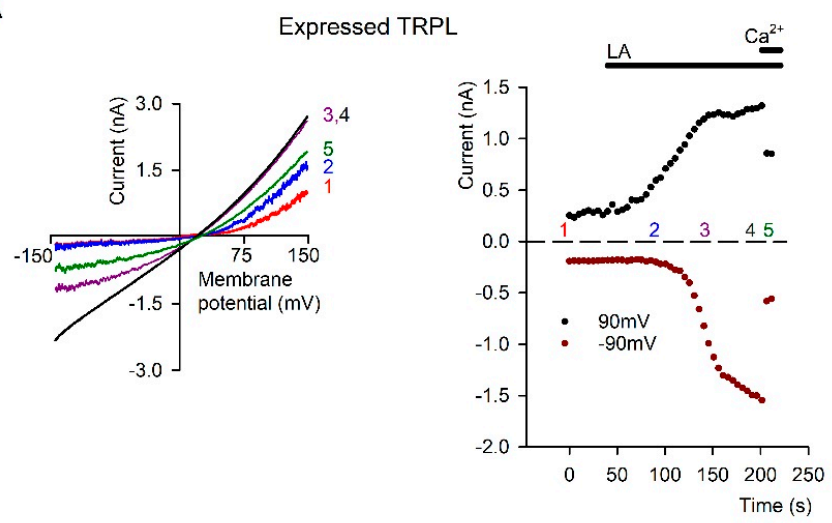

B

Native TRPL
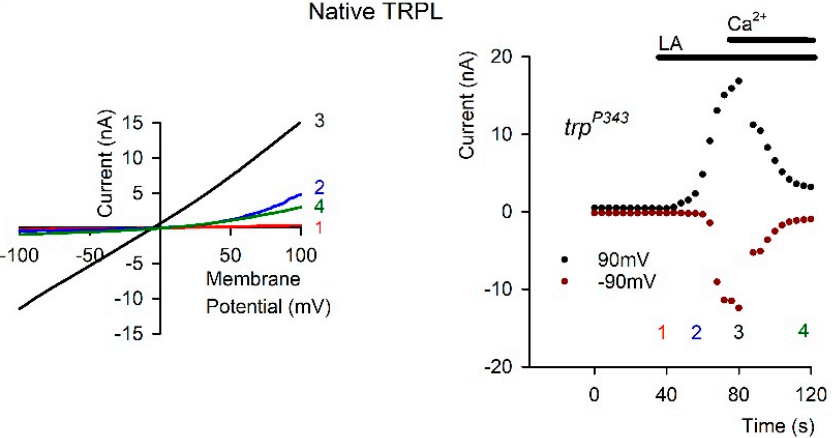

Figure 4. Linoleic Acid (LA) removed Open Channel Block (OCB) from TRPL Channels: (A) Left, Representative I-V curves measured from S2 cells by whole cell patch clamp recordings using voltage ramps from $-150 \mathrm{mV}$ to $150 \mathrm{mV}$ in 1s. The typical outward rectification of the TRPL channels (red curve 1) was modified to a linear I-V curve after application of $40 \mu \mathrm{M}$ Linoleic Acid (LA, black curve 4). The effect at positive membrane potentials preceded that of negative membrane potentials (Curves 2 and 3, blue and purple respectively, see also 1A right). Application of $5 \mathrm{mM} \mathrm{Ca}^{2+}$ restored the outward rectifying I-V curve (green curve 5). Right: The current values at $90 \mathrm{mV}$ (black dots) and $-90 \mathrm{mV}$ (dark red dots) are presented as a function of time. The numbers correspond to the curves presented in the left $(n=15)$. (B). Left, Representative I-V curves measured as in A from mutant Drosophila ommatidia that express only TRPL channels $\left(\operatorname{trp}^{\mathrm{P} 343}\right)$. In darkness the TRPL channels were closed (red curve 1). After application of $60 \mu \mathrm{M}$ LA, a linear I-V curve was obtained (black curve 3). The effect of LA at positive membrane potentials preceded the effect at negative membrane potentials in a similar manner to expressed channels (blue curve 2). Application of $10 \mathrm{mM} \mathrm{Ca}^{2+}$ blocked the TRPL channel (green curve 4, left), ruling out the possibility that the linear I-V curve was due to leak current. Right, the effect of LA on the current is presented as a function of time at $90 \mathrm{mV}$ (black dots) and $-90 \mathrm{mV}$ (dark red dots). The numbers correspond to the curves presented in the left $(n=5)$. The I-V curve of the LIC is presented in pink (the maximal light intensity was attenuated by $2 \log$ units). (From [78], Copyright 2000 Society for Neuroscience). 

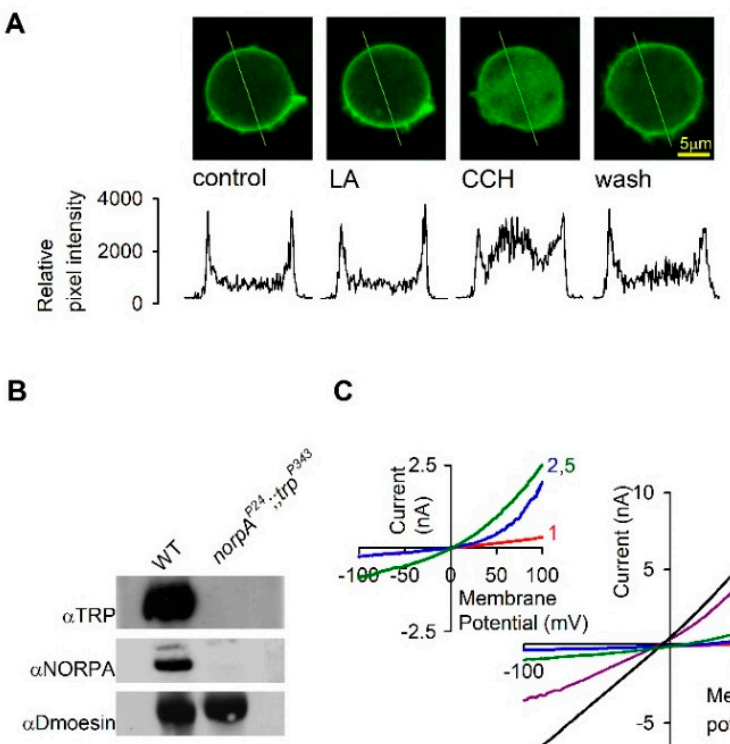

C

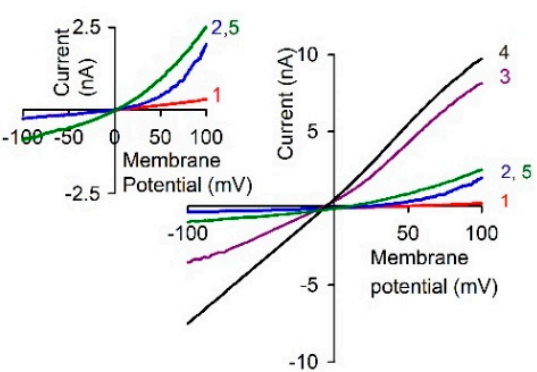

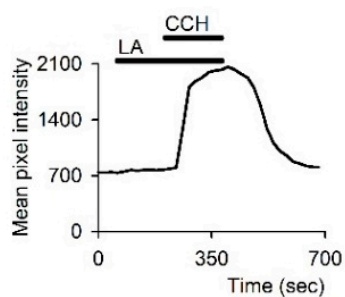

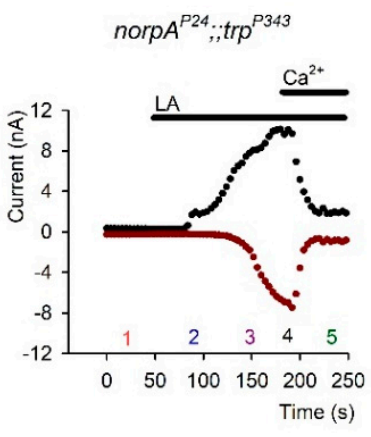

Figure 5. The action of Linoleic Acid (LA) is not mediated via PLC: (A): PLC activity was monitored by using $\mathrm{S} 2$ cells expressing the Drosophila muscarinic receptor (DM1) and eGFP-PH, which binds to $\mathrm{PIP}_{2}$ and $\mathrm{IP}_{3}$. Application of $50 \mu \mathrm{M}$ LA, under conditions which activated the channels, did not elicit any change in the eGFP-PH distribution, as monitored by confocal images of the GFP fluorescence (LA) relative to control. Application of carbachol $(\mathrm{CCH})$ elicited a robust translocation of eGFP-PH to the cytosol, which was reversed by $\mathrm{CCH}$ removal (wash), thus indicating activation of PLC $(n=6)$. The relative fluorescence intensity at a cross section of the cell (marked by line) is also presented below the confocal images. The time course of the fluorescence changes measured in the cytosol is presented on the right. (B). Western blot analysis of heads homogenate of dark raised WT and norp $A^{p 24}$; trp $^{P 343}$ double null mutant flies. Head membrane was extracted with SDS buffer and subjected to Western blot analysis with antibodies specific for the Drosophila proteins TRP, NORPA and Dmoesin as indicated. No TRP and NORPA proteins were detected in the norp $A^{p 24}$; trp ${ }^{\text {P343 }}$ double mutant. (C). Left, Representative I-V curves measured by whole cell recordings from photoreceptors of the norp $A^{P 24}$; $\operatorname{trp}^{P 343}$ mutant lacking PLC and the TRP channel (see Figure 5B). In darkness the TRPL channels are closed (red curve 1). The effect of the $60 \mu \mathrm{M}$ LA was not altered by the absence of PLC and a linear I-V curve was obtained (black curve 4). The effect of LA at positive membrane potentials preceded that of negative membrane potentials (Curves 2 and 3, blue and purple respectively) in a similar manner to the results of S2. Application of $10 \mathrm{mM} \mathrm{Ca}^{2+}$ restored the outward rectifying I-V curve (green curve 5). Inset, enlargement of curves 1, 2 and 5, demonstrating more clearly the outward rectification. Right, the effect of LA on the current is presented at $90 \mathrm{mV}$ (black dots) and $-90 \mathrm{mV}$ (dark red dots) as a function of time. The numbers correspond to the curves presented in the left $(n=4)$. (From [78], Copyright 2000 Society for Neuroscience).

Most of the studies on PUFA activation of the Drosophila channels have been carried out in tissue culture cells. We and others have performed a significant part of the research on TRPL channels in cell culture expression systems with the aim of gaining insight into channel activation mechanism directly by single channel analysis. Extensive effort was devoted to express functional Drosophila TRP channels in tissue culture cells with no success. The few studies reporting functional heterologous TRP expression failed to capture the typical physiological properties of TRP as illustrated in whole cell recordings of the native photoreceptor cells ([5,79] see Figures 3 and 4) and showed linear leak currents [80-82]. In contrast, heterologous expression of the TRPL channels accurately captured the physiological response of the native photoreceptor cells [83,84] (Figure 4). The use of expression systems for TRPL channel research has several advantages: (1) the channels are, for the most part, easily expressed in a functional manner. (2) Biophysical properties such as conductance, mean open time, and permeability are readily 
obtained [85]. These rigorous studies revealed that the typical outward rectification of the TRPL channels [84] results from a voltage dependent divalent open channel block mechanism [78,85]. Interestingly, application of PUFA (e.g., linoleic acid, LA) removed this divalent open channel block in the presence of divalent cations by a still unclear voltage independent mechanism (Figure 4). In general, it is important to compare the activity of a specific TRP channel in a native system with that obtained from an expression system. Indeed, many of the physiological properties observed in the photoreceptors were readily obtained and verified in expression systems. Functional expression of the TRPL channels was shown in a variety of cells including Spodoptera frugiperda 9 (Sf9; [86,87], Schneider 2 (S2; [77,85], and COS [88] cells and resulted in constitutively active channels, whereas the expression of the channels in Human Embryonic Kidney (HEK) cells resulted in channels that are in their closed state [88,89], mimicking the state of the TRPL channels in photoreceptor cells, in the dark. The constitutive activity of the expressed TRPL channel can be further enhanced by activation of the endogenous transduction cascade and might be related to the gating of this channel. However, it is still unclear what leads to this spontaneous activity of the TRPL channel in these expression systems, which might be important for understanding channel activation. Constitutive activity of channels can be attributed to the direct activation of the channel, for example via the lipid composition of the plasma membrane [90], or to the constitutive activation of a known or unknown element upstream to the channel. In this respect, the Drosophila TRPL channel expressed in S2 cells might be affected by constitutively active endogenous phospholipase C (PLC). However, PLC inhibition (with U-73122 or by a PLC mutation) did not abolish the constitutive activity of TRPL expressed in S2 cells. In addition, high expression levels of the channel also result in deregulation of the channels and may result in constitutive activity. The observation that the TRP/TRPL channels readily undergo a constitutively active state both in tissue culture cells and in vivo (e.g., spontaneously, or by DAG accumulation, respectively) may suggest that the threshold for channel activation is low, thereby having an important implication on photomechanical activation of the channels (see below).

A question arises as to whether PUFA activation of the channels in the photoreceptor cells reflects the physiological mechanism of channel activation. Supporting evidence was provided by isolation of the Inactivation No Afterpotential E (inaE) mutant by Pak and colleagues [91]. The inaE gene was identified as encoding a homologue of the mammalian sn-1 type DAG lipase, which, rather than PUFAs, releases mono-acyl glycerol (MAGs) and, are at best, weak and slowly acting channel agonists when applied exogenously (Hardie, unpublished results, see [49]). Furthermore, the inaE gene product immunolocalizes to the cell body with occasional puncta in the rhabdomere [91]. Mutant flies, expressing low levels of the inaE gene product, have an abnormal light response, while the activation of the light sensitive channels was not prevented [91]. The discovery of the InaE gene was an important step in the endeavor to elucidate lipids regulation of the channels (see reviews by and [52]). However, for PUFA generation, either an sn-2 DAG lipase or an additional enzyme (MAG lipase) would be required, but there is no evidence of either in Drosophila photoreceptors and there is also no evidence that PUFAs are even generated in response to illumination [74].

\section{Photomechanical Gating of the TRP/TRPL Channels}

Many studies have shown that membrane-protein function is regulated by the composition of the lipid bilayer in which the proteins are embedded. The commonality of the changes in protein function by changes in their lipid environment suggests an underlying physical mechanism, and at least some of the changes are caused by altered bilayer physical properties [92]. Although TRP/TRPL channel activation by PUFA is most likely not a physiological mechanism, it provides an important insight into mechanisms by which membrane lipid modulation by a variety of PUFAs causes dramatic effects on TRP/TRPL channel gating and its properties. Accordingly, we previously showed that removal of open channel block (OCB) from TRP/TRPL channels by PUFA resulted from an increased flow rate of the blocking divalent cations through the channel pore [78]. Modulation of the interface of the 
channel and its surrounding membrane lipids might underlie the increase in the flow rate of the blocking cations and the removal of the OCB. We applied various methods to modify membrane lipid properties around the TRPL channel, including: stretch of the plasma membrane by hypoosmotic solutions, sequestration of $\mathrm{PIP}_{2}$ by polylysine, and application of various lipids. Alternatively, we blocked PUFA action by the GsMTx-4 tarantula toxin, a specific inhibitor of mechanosensitive channels, which acts on the channel-membrane lipid interface $[93,94]$. These results thus suggested that lipids do not affect the TRPL channel as second messengers but rather as modifiers of membrane lipid-channel interactions [78].

Hardie and Franze suggested that light-activated PLC, which hydrolyzes membrane $\mathrm{PIP}_{2}$ and generates DAG activates the TRP/TRPL channels by change in membrane tension. This membrane tension results from the conversion of $\mathrm{PIP}_{2}$ with a large hydrophilic head group into DAG, having a minute hydrophilic head group, causing changes in membrane lipid packing. This conclusion followed from a dramatic observation that light caused a fast contraction in the fly photoreceptors. They quantitated the light induced movement with atomic force microscopy and show that it reaches a peak of $\sim 400 \mathrm{~nm}$, with an onset that precedes the onset of the light induced current. This photoreceptor contraction depended on the enzymatic activity of PLC that was blocked by the norpA mutation, but not on TRP/TRPL channel activity [95]. To support their hypothesis, Hardie and Franze showed that light can activate a mechanically gated ion channel-gramicidin-when inserted in the photoreceptor plasma membrane. To show that membrane tension gates the TRP/TRPL channels, they exposed the photoreceptors to hypo-osmotic solutions, anticipating that it will exert a similar effect as change in membrane lipid packing similar to $\mathrm{PIP}_{2}$ hydrolysis. In addition, similar to the results reported by Parnas et al. [78], hypo-osmotic solutions, though not sufficient to activate the TRPL/TRP channels, potentiated channels openings. Consistent with the interpretation that the generation of membrane tension is required for channels gating, they applied several cationic amphipaths that affected the light induced current in the expected direction. The above studies support the interesting possibility that specific changes in the physical properties of the lipid bilayer generating changes in protein-lipid interaction and an increase in membrane tension constitute a mechanical stimulus that opens TRP/TRPL channels during phototransduction. Furthermore, perhaps because of low activation threshold of TRP channels, changes in membrane tension induced by enzymatic reaction may be sufficient to gate the channels by change in membrane lipid packing, a mechanism that has not been anticipated to have any role in the mechanosensitivity of these channels.

\section{Lipid Rafts and Modulation of TRPL Channel Activity by Cholesterol}

Lipid rafts are membrane microdomains rich with sterols, sphingolipids, and specific proteins. Lipid rafts have been found in all types of cells. It has been generally agreed that lipid rafts generate signaling platforms by assembling in close proximity to different signaling molecules for the optimal function of signal transduction cascades [96]. Many signaling proteins including ion channels have been found to localize in lipid rafts, while the association with rafts was required for the regulation of some integral membrane protein activities [97,98]. The actions of lipid rafts are often associated with the effect of cholesterol on membrane structure or directly on membrane proteins (see below). Channels have been found in detergent-resistant membrane (DRM) fractions, indicating the inclusion of channels in lipid rafts [99].

A study in Drosophila revealed dynamic organization of signaling components in DRM of Drosophila photoreceptors. It was found that the Drosophila-specific INAD scaffold protein $[100,101]$ and its target proteins undergo light-induced recruitment to DRM rafts [102]. Reduction of the Drosophila sterol, ergosterol (see below), a key component of lipid rafts in Drosophila, resulted in a loss of INAD-signaling complexes associated with DRM fractions. Genetic analysis demonstrated that translocation of INAD-signaling complexes to DRM rafts required activation of the entire phototransduction cascade, while constitutive activation of the light-activated channels resulted in recruitment of complexes to DRM rafts 
in the dark. Mutations affecting INAD and TRP showed that INAD-TRP interaction is required for translocation of components to DRM rafts [102].

Unlike mammals, insects are unable to synthesize sterols [103] and Drosophila melanogaster is totally dependent on exogenously provided sterols, in the form of ergosterol obtained from a yeast diet [102,104]. Nevertheless, several enzymes of Drosophila do not differentiate between endogenous ergosterol and exogenous cholesterol [105]. Many studies have shown the involvement of cholesterol in the modulation of ion channels function. An efficient method to modulate the content of plasma membrane sterols is by methyl- $\beta$-cyclodextrin $(M \beta C D)$, which is a cyclic oligosaccharide $[106,107]$. The $\beta$-cyclodextrins (7 glucose units) have high affinity for encapsulating both cholesterol and ergosterol [107]. $\mathrm{M} \beta C D$ is quite specific, allowing enrichment or a relatively rapid sequestration of cholesterol/ergosterol from living cells. Sterol-saturated $\mathrm{M} \beta \mathrm{CD}$ is efficient as a sterol donor. The degree of cholesterol enrichment is between $\sim 30 \%$ to $\sim 3$-fold, according to the type of cell $[108,109]$. When cells are incubated with high concentration of "empty" M $\beta C D$ (5-10 mM) for hours ( $>2 \mathrm{~h}$ ), 80-90\% of total cellular cholesterol can be sequestered $[108,110]$. The amount of cholesterol sequestration from different cell types is a highly variable parameter [109-112]. Cholesterol sequestration leads to a dis-association of proteins from lipid rafts [113-115] and to a decrease in the clustering of raft-associated molecules [116]. It was shown that $\beta C D$ s sequestered cholesterol from both cholesterol-rich and cholesterol-poor membrane domains [117-120]. In silico analysis revealed that cholesterol adopts multiple poses in a "cloud", rather than occupying a single conformation at a highly flexible binding site of the channel [6], while the high structural similarities between cholesterol and ergosterol suggest that this is also likely to be the case for ergosterol. It was also suggested that cholesterol sequestration leads to perturbation of specific lipid environments. Previous observations have suggested reversible targeting of Drosophila [102] and mammalian TRPC channels to the cholesterol-rich membrane environment of lipid rafts. This led to the suggestion that the relatively fast (many seconds) inhibitory effects of cholesterol depletion by M $\beta C D$ on mammalian TRPC channel activity may result from disruption of lipid raft architecture [44]. When Drosophila S2 cells heterologously expressing TRPL were perfused with $\mathrm{M} \beta C D$, the TRPL-dependent current was rapidly abolished in less than $100 \mathrm{~s}$ (Figure 6 [121]), which corresponds with the fast kinetic phase of cholesterol sequestration experiments in cells [122]. Modulation of TRP channels function by direct binding of cholesterol to the channels was suggested for mammalian TRPV1 channel [123]. Cholesterol-protein interactions have been extensively studied and specific sterol recognition elements such as the cholesterol recognition amino acid consensus or cholesterol binding pockets have been demonstrated in ion channels [124]. However, these motifs create a bias, compelling researchers to focus solely on these sequences instead of performing a bias-free analyses. Indeed, recent studies on Kir 2.2 channels have shown that these motifs do not always reflect the real interactions of cholesterol with the channels [6]. 
A

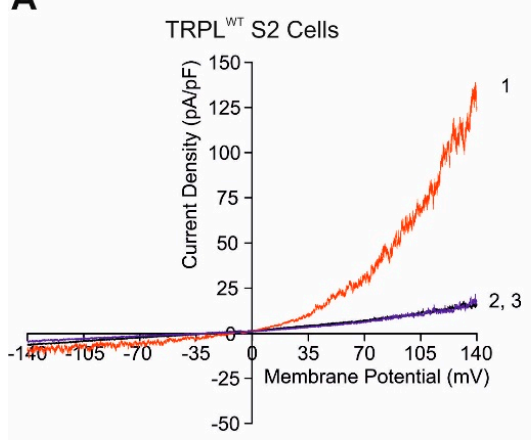

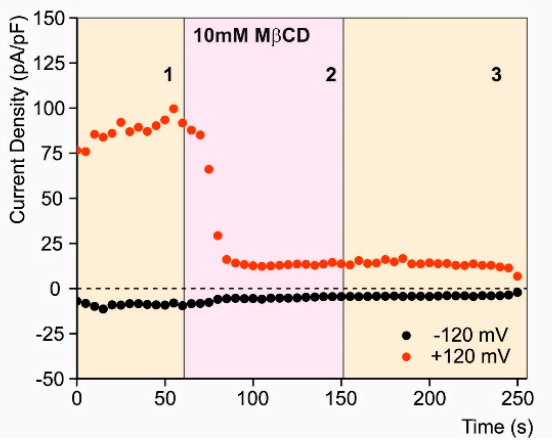

C

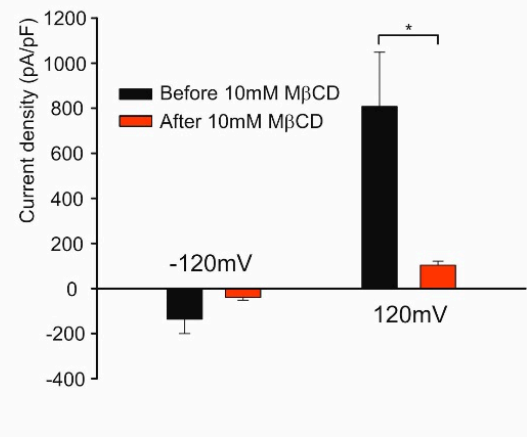

Figure 6. Sequestration of cholesterol abolished the constitutive activity of TRPL channels. (A) Current-voltage relationships (I-V curves) measuring TRPL-dependent currents I-V curves obtained in response to voltage ramp (of $1 \mathrm{~s}$ duration) from S2 cells expressing TRPL and showing basal channel activity with strong outward rectification, typical for TRPL-dependent current (1). The TRPL channel activity was highly reduced after perfusion with $10 \mathrm{mM} \mathrm{M} \beta C D(2)$ and the effect was irreversible, even after washout of $\mathrm{M} \beta C D(3)(n>10)$. (B) Time course of the M $\beta C D$ effects on TRPL currents in S2 cells. Current densities are shown as a function of time. Series of I-V curves were derived from repeatedly applied voltage ramps every $5 \mathrm{~s}$ and currents were measured at $\pm 120 \mathrm{mV}$ holding potentials as a function of time under the various experimental conditions as indicated. The numbers correspond to the numbers on the I-V curves in (A). (C) Statistics of the cholesterol depletion experiments in S2 cells. Cholesterol depletion by M $\beta C D$ had a significant effect on the positive TRPL currents at $120 \mathrm{mV}\left(n=5\right.$, values are average $\pm \mathrm{SEM}$, paired Student $t$-test, $\left.{ }^{*} p \leq 0.05\right)$. (From [121]).

In recent experiments we sequestered cholesterol by $\mathrm{M} \beta \mathrm{CD}$ from the plasma membrane of S2 cells stably expressing TRPL. The constitutively active expressed TRPL channels (Figure 4), which showed a current-voltage relationship (I-V curves) with a marked TRPL dependent current at $+80 \mathrm{mV}$ were completely suppressed by the sequestration of cholesterol from the plasma membrane by $M \beta C D$. When the constitutive activity was suppressed, application of linoleic acid, the potent activator of TRP and TRPL channels [77,78] enhanced channel opening (data not shown). We also examined the effect of ergosterol sequestration from the plasma membrane of Drosophila photoreceptors and found a dramatic effect of ergosterol sequestration on the ability of the channels to open (data not shown).

\section{Concluding Remarks}

Despite many efforts over the years, the gating mechanism of the Drosophila TRP/TRPL channels still poses a long-standing enigma. The findings that mammalian TRPC channels can be activated by exogeneous application of DAG together with the solved atomic structures of mammalian TRPC channels by cryo-EM constitute major progress towards understanding TRPC channel gating. Nevertheless, Drosophila retina is a highly valued preparation for investigating the roles of TRP/TRPL channels under physiological conditions. This is due to their high expression levels and their known functional role as the light-activated channels. There remains no comparable preparation for the mammalian TRPC channels that contains a TRP-enriched tissue combined with the power of the Drosophila molecular genetics and the accuracy of light activation. Moreover, studies of Drosophila phototransduction revealed that under physiological conditions, Drosophila TRP operates as an essential part of a multimolecular signaling complex. There are indications that mammalian TRPC channels also operate in a similar manner, but it is difficult to study these mechanisms in the native mammalian systems because of the scarcity of these signaling proteins in the native systems.

Crucial unsolved questions in Drosophila photoreceptor physiology are related to the mechanism by which DAG accumulation following DGK inhibition activates the channels. 
In particular, why exogeneous application of DAG to an excised signaling membrane activates the channels in orders of magnitude slower than light activation in the intact photoreceptor cell. The use of photoactivated DAG analogues [125] may help in solving this question.

An available Drosophila mutant in which the TRP channels are constitutively active (i.e., the $\operatorname{trp}^{P 365}$ mutant) is a highly valuable tool for investigating TRP gating in the future, which can be used together with the solved atomic structure of mammalian TRPCs. In addition, even if PUFA is not the native second messenger of excitation, its robust effect of opening the TRP/TRPL channels in the dark in vivo and TRPL in tissue culture cells can be studied in detail and provide useful information on channel gating.

Finally, the photomechanical gating mechanism of TRP/TRPL channels that was put forward by Hardie and colleagues needs to be revisited. According to this model and the supporting evidence, light-induced $\mathrm{PIP}_{2}$ hydrolysis by PLC converts a phospholipid with a large hydrophilic head group $\left(\mathrm{PIP}_{2}\right)$ into DAG with a minute hydrophilic head group. This enzymatic reaction leads to a generation of a measurable force that may open the channels mechanically.

Funding: This research was funded by Israel Science Foundation (ISF) grant number 368/19 and by United states-Israel Binational Science Foundation (BSF) grant number 201514. The APC was funded by ISF.

Acknowledgments: This research was supported by grants from the Israel Science Foundation (ISF), and the United states-Israel Binational Science Foundation (BSF).

Conflicts of Interest: Authors declare no conflict of interest.

\section{References}

1. Damann, N.; Voets, T.; Nilius, B. TRPs in our senses. Curr. Biol. 2008, 18, R880-R889. [CrossRef] [PubMed]

2. Hardie, R.C.; Raghu, P. Visual transduction in Drosophila. Nature 2001, 413, 186-193. [CrossRef] [PubMed]

3. Katz, B.; Minke, B. Drosophila photoreceptors and signaling mechanisms. Front. Cell. Neurosci. 2009, 3, 2. [CrossRef]

4. Kiselyov, K.; Patterson, R.L. The integrative function of TRPC channels. Front. Biosci. 2009, 14, 45-58. [CrossRef] [PubMed]

5. Minke, B.; Parnas, M. Insights on TRP channels from in vivo studies in Drosophila. Annu. Rev. Physiol. 2006, 68, 649-684. [CrossRef]

6. Barbera, N.; Ayee, M.A.A.; Akpa, B.S.; Levitan, I. Molecular Dynamics Simulations of Kir2.2 Interactions with an Ensemble of Cholesterol Molecules. Biophys. J. 2018, 115, 1264-1280. [CrossRef]

7. Yoshioka, T.; Inoue, H.; Hotta, Y. Defective phospholipid metabolism in the retinular cell membrane of norpA (no receptor potential) visual transduction mutants of Drosophila. Biochem. Biophys. Res. Commun. 1983, 111, 567-573. [CrossRef]

8. Yoshioka, T.; Inoue, H.; Hotta, Y. Absence of phosphatidylinositol phosphodiesterase in the head of a Drosophila visual mutant, norpA (no receptor potential A). J. Biochem. Tokyo 1985, 97, 1251-1254. [CrossRef]

9. Inoue, H.; Yoshioka, T.; Hotta, Y. Membrane-associated phospholipase C of Drosophila retina. J. Biochem. Tokyo 1988, 103, 91-94. [CrossRef]

10. Devary, O.; Heichal, O.; Blumenfeld, A.; Cassel, D.; Suss, E.; Barash, S.; Rubinstein, C.T.; Minke, B.; Selinger, Z. Coupling of photoexcited rhodopsin to inositol phospholipid hydrolysis in fly photoreceptors. Proc. Natl. Acad. Sci. USA 1987, 84, 6939-6943. [CrossRef]

11. Deland, M.C.; Pak, W.L. Reversibly temperature sensitive phototransduction mutant of Drosophila melanogaster. Nat. New Biol. 1973, 244, 184-186. [CrossRef]

12. Selinger, Z.; Minke, B. Inositol lipid cascade of vision studied in mutant flies. Cold Spring Harb. Symp. Quant. Biol. 1988, 53 Pt 1, 333-341. [CrossRef] [PubMed]

13. Bloomquist, B.T.; Shortridge, R.D.; Schneuwly, S.; Perdew, M.; Montell, C.; Steller, H.; Rubin, G.; Pak, W.L. Isolation of a putative phospholipase C gene of Drosophila, norpA, and its role in phototransduction. Cell 1988, 54, 723-733. [CrossRef]

14. Kohn, E.; Katz, B.; Yasin, B.; Peters, M.; Rhodes, E.; Zaguri, R.; Weiss, S.; Minke, B. Functional Cooperation between the IP3 Receptor and Phospholipase C Secures the High Sensitivity to Light of Drosophila Photoreceptors In Vivo. J. Neurosci. 2015, 35, 2530-2546. [CrossRef] [PubMed]

15. Pearn, M.T.; Randall, L.L.; Shortridge, R.D.; Burg, M.G.; Pak, W.L. Molecular, biochemical, and electrophysiological characterization of Drosohpila norpA mutannts. J. Biol. Chem. 1996, 271, 4937-4945. [CrossRef] [PubMed]

16. Cook, B.; Bar, Y.M.; Cohen-Ben, A.H.; Goldstein, R.E.; Paroush, Z.; Selinger, Z.; Minke, B. Phospholipase C and termination of G-protein-mediated signalling in vivo. Nat. Cell Biol. 2000, 2, 296-301. [CrossRef] 
17. Waldo, G.L.; Ricks, T.K.; Hicks, S.N.; Cheever, M.L.; Kawano, T.; Tsuboi, K.; Wang, X.; Montell, C.; Kozasa, T.; Sondek, J.; et al. Kinetic Scaffolding Mediated by a Phospholipase C-\{beta\} and Gq Signaling Complex. Science 2010, 330, 974-980. [CrossRef]

18. Yeandle, S.; Spiegler, J.B. Light-evoked and spontaneous discrete waves in the ventral nerve photoreceptor of Limulus. J. Gen. Physiol. 1973, 61, 552-571. [CrossRef]

19. Rhee, S.G. Regulation of phosphoinositide-specific phospholipase C. Annu. Rev. Biochem. 2001, 70, 281-312. [CrossRef]

20. Essen, L.O.; Perisic, O.; Cheung, R.; Katan, M.; Williams, R.L. Crystal structure of a mammalian phosphoinositide-specific phospholipase C delta. Nature 1996, 380, 595-602. [CrossRef]

21. Essen, L.O.; Perisic, O.; Katan, M.; Wu, Y.; Roberts, M.F.; Williams, R.L. Structural mapping of the catalytic mechanism for a mammalian phosphoinositide-specific phospholipase C. Biochemistry 1997, 36, 1704-1718. [CrossRef] [PubMed]

22. Running Deer, J.L.; Hurley, J.B.; Yarfitz, S.L. G protein control of Drosophila photoreceptor phospholipase C. J. Biol. Chem. 1995, 270, 12623-12628. [CrossRef] [PubMed]

23. Hardie, R.C. Inhibition of phospholipase $C$ activity in Drosophila photoreceptors by 1,2-bis(2-aminophenoxy)ethane $\mathrm{N}, \mathrm{N}, \mathrm{N}^{\prime}, \mathrm{N}^{\prime}$ tetraacetic acid (BAPTA) and di-bromo BAPTA. Cell Calcium 2005, 38, 547-556. [CrossRef] [PubMed]

24. Minke, B.; Agam, K. TRP gating is linked to the metabolic state and maintenance of the Drosophila photoreceptor cells. Cell Calcium 2003, 33, 395-408. [CrossRef]

25. Oberwinkler, J.; Stavenga, D.G. Calcium transients in the rhabdomeres of dark- and light-adapted fly photoreceptor cells. $J$. Neurosci. 2000, 20, 1701-1709. [CrossRef]

26. Postma, M.; Oberwinkler, J.; Stavenga, D.G. Does $\mathrm{Ca}^{2+}$ reach millimolar concentrations after single photon absorption in Drosophila photoreceptor microvilli? Biophys. J. 1999, 77, 1811-1823. [CrossRef]

27. Gu, Y.; Oberwinkler, J.; Postma, M.; Hardie, R.C. Mechanisms of light adaptation in Drosophila photoreceptors. Curr. Biol. 2005, 15, 1228-1234. [CrossRef]

28. Hardie, R.C.; Raghu, P.; Moore, S.; Juusola, M.; Baines, R.A.; Sweeney, S.T. Calcium influx via TRP channels is required to maintain PIP 2 levels in Drosophila photoreceptors. Neuron 2001, 30, 149-159. [CrossRef]

29. Katz, B.; Minke, B. Phospholipase C-Mediated Suppression of Dark Noise Enables Single-Photon Detection in Drosophila Photoreceptors. J. Neurosci. 2012, 32, 2722-2733. [CrossRef]

30. Cook, B.; Minke, B. TRP and calcium stores in Drosophila phototransduction. Cell Calcium 1999, 25, 161-171. [CrossRef]

31. Hardie, R.C.; Minke, B. The trp gene is essential for a light-activated $\mathrm{Ca}^{2+}$ channel in Drosophila photoreceptors. Neuron 1992, 8 , 643-651. [CrossRef]

32. Lu, C.; Vihtelic, T.S.; Hyde, D.R.; Li, T. A neuronal-specific mammalian homolog of the Drosophila retinal degeneration B gene with expression restricted to the retina and dentate gyrus. J. Neurosci. 1999, 19, 7317-7325. [CrossRef] [PubMed]

33. Milligan, S.C.; Alb, J.G.; Elagina, R.B.; Bankaitis, V.A.; Hyde, D.R. The phosphatidyl inositol transfer protein domain of Drosophila retinal degeneration B protein is essential for photoreceptor cell survival and recovery from light stimulation. J. Cell Biol. 1997, 139, 351-363. [CrossRef] [PubMed]

34. Minke, B.; Selinger, Z. Inositol lipid pathway in fly photoreceptors: Excitation, calcium mobilization and retinal degeneration. In Progress in Retinal Research; Osborne, N.A., Chader, G.J., Eds.; Pergamon Press Oxford: Oxford, UK, $1991 ;$ pp. 99-124.

35. Hardie, R.C. Calcium signalling: Setting store by calcium channels. Curr. Biol. 1996, 6, 1371-1373. [CrossRef]

36. Zhang, I.; Hu, H. Store-Operated Calcium Channels in Physiological and Pathological States of the Nervous System. Front. Cell. Neurosci. 2020, 14, 600758. [CrossRef] [PubMed]

37. Liedtke, W.B.; Heller, S. TRP Ion Channel Function in Sensory Transduction and Cellular Signaling Cascades; CRC Press: Boca Raton, FL, USA, 2007.

38. Hardie, R.C. Excitation of Drosophila photoreceptors by BAPTA and ionomycin: Evidence for capacitative Ca ${ }^{2+}$ entry? Cell Calcium 1996, 20, 315-327. [CrossRef]

39. Raghu, P.; Colley, N.J.; Webel, R.; James, T.; Hasan, G.; Danin, M.; Selinger, Z.; Hardie, R.C. Normal phototransduction in Drosophila photoreceptors lacking an InsP 3 receptor gene. Mol. Cell. Neurosci. 2000, 15, 429-445. [CrossRef]

40. Acharya, J.K.; Jalink, K.; Hardy, R.W.; Hartenstein, V.; Zuker, C.S. InsP 3 receptor is essential for growth and differentiation but not for vision in Drosophila. Neuron 1997, 18, 881-887. [CrossRef]

41. Liu, C.-H.; Chen, Z.; Oliva, M.K.; Luo, J.; Collier, S.; Montell, C.; Hardie, R.C. Rapid Release of Ca ${ }^{2+}$ from Endoplasmic Reticulum Mediated by $\mathrm{Na}^{+} / \mathrm{Ca}^{2+}$ Exchange. J. Neurosci. 2020, 40, 12. [CrossRef]

42. Hardie, R.C. Regulation of Drosophila TRP channels by lipid messengers. Novartis. Found. Symp. 2004, 258, 160-167.

43. Katz, B.; Minke, B. The Drosophila light-activated TRP and TRPL channels-Targets of the phosphoinositide signaling cascade. Prog. Retin. Eye Res. 2018, 66, 200-219. [CrossRef] [PubMed]

44. Svobodova, B.; Groschner, K. Reprint of "Mechanisms of lipid regulation and lipid gating in TRPC channels". Cell Calcium 2016, 60, 133-141. [CrossRef] [PubMed]

45. Stark, W.S.; Lin, T.N.; Brackhahn, D.; Christianson, J.S.; Sun, G.Y. Fatty acids in the lipids of Drosophila heads: Effects of visual mutants, carotenoid deprivation and dietary fatty acids. Lipids 1993, 28, 345-350. [CrossRef] [PubMed]

46. Stark, W.S.; Lin, T.N.; Brackhahn, D.; Christianson, J.S.; Sun, G.Y. Phospholipids in Drosophila heads: Effects of visual mutants and phototransduction manipulations. Lipids 1993, 28, 23-28. [CrossRef]

47. Eroglu, C.; Brugger, B.; Wieland, F.; Sinning, I. Glutamate-binding affinity of Drosophila metabotropic glutamate receptor is modulated by association with lipid rafts. Proc. Natl. Acad. Sci. USA 2003, 100, 10219-10224. [CrossRef] 
48. Rietveld, A.; Neutz, S.; Simons, K.; Eaton, S. Association of sterol- and glycosylphosphatidylinositol-linked proteins with Drosophila raft lipid microdomains. J. Biol. Chem. 1999, 274, 12049-12054. [CrossRef] [PubMed]

49. Randall, A.S.; Liu, C.H.; Chu, B.; Zhang, Q.; Dongre, S.A.; Juusola, M.; Franze, K.; Wakelam, M.J.; Hardie, R.C. Speed and sensitivity of phototransduction in Drosophila depend on degree of saturation of membrane phospholipids. J. Neurosci. 2015, 35, 2731-2746. [CrossRef]

50. Julius, D. From peppers to peppermints: Natural products as probes of the pain pathway. Harvey Lect. 2005, 101, 89-115.

51. Berridge, M.J. Inositol trisphosphate and calcium signalling. Nature 1993, 361, 315-325. [CrossRef]

52. Raghu, P.; Yadav, S.; Mallampati, N.B. Lipid signaling in Drosophila photoreceptors. Biochim. Biophys. Acta 2012, 1821, 1154-1165. [CrossRef]

53. Masai, I.; Okazaki, A.; Hosoya, T.; Hotta, Y. Drosophila retinal degeneration A gene encodes an eye-specific diacylglycerol kinase with cysteine-rich zinc-finger motifs and ankyrin repeats. Proc. Natl. Acad. Sci. USA 1993, 90, 11157-11161. [CrossRef] [PubMed]

54. Masai, I.; Suzuki, E.; Yoon, C.S.; Kohyama, A.; Hotta, Y. Immunolocalization of Drosophila eye-specific diacylgylcerol kinase, $\operatorname{rdgA}$, which is essential for the maintenance of the photoreceptor. J. Neurobiol. 1997, 32, 695-706. [CrossRef]

55. Wu, L.; Niemeyer, B.; Colley, N.; Socolich, M.; Zuker, C.S. Regulation of PLC-mediated signalling in vivo by CDP-diacylglycerol synthase. Nature 1995, 373, 216-222. [CrossRef] [PubMed]

56. Vihtelic, T.S.; Hyde, D.R.; O'Tousa, J.E. Isolation and characterization of the Drosophila retinal degeneration B (rdgB) gene Genetics 1991, 127, 761-768. [CrossRef] [PubMed]

57. Cockcroft, S.; Raghu, P. Topological organisation of the phosphatidylinositol 4,5-bisphosphate-phospholipase C resynthesis cycle: PITPs bridge the ER-PM gap. Biochem. J. 2016, 473, 4289-4310. [CrossRef] [PubMed]

58. Cockcroft, S.; Garner, K.; Yadav, S.; Gomez-Espinoza, E.; Raghu, P. RdgB $\alpha$ reciprocally transfers PA and PI at ER-PM contact sites to maintain PI $(4,5) \mathrm{P} 2$ homoeostasis during phospholipase C signalling in Drosophila photoreceptors. Biochem. Soc. Trans. 2016, 44, 286-292. [CrossRef]

59. Raghu, P.; Basak, B.; Krishnan, H. Emerging perspectives on multidomain phosphatidylinositol transfer proteins. Biochim. Biophys. Acta Mol. Cell Biol. Lipids 2021, 1866, 158984. [CrossRef]

60. Garcia-Murillas, I.; Pettitt, T.; Macdonald, E.; Okkenhaug, H.; Georgiev, P.; Trivedi, D.; Hassan, B.; Wakelam, M.; Raghu, P. lazaro encodes a lipid phosphate phosphohydrolase that regulates phosphatidylinositol turnover during Drosophila phototransduction Neuron 2006, 49, 533-546. [CrossRef]

61. Kwon, Y.; Montell, C. Dependence on the Lazaro phosphatidic acid phosphatase for the maximum light response. Curr. Biol. 2006, 16, 723-729. [CrossRef]

62. LaLonde, M.M.; Janssens, H.; Rosenbaum, E.; Choi, S.Y.; Gergen, J.P.; Colley, N.J.; Stark, W.S.; Frohman, M.A. Regulation of phototransduction responsiveness and retinal degeneration by a phospholipase D-generated signaling lipid. J. Cell Biol. 2005, 169, 471-479. [CrossRef]

63. Thakur, R.; Panda, A.; Coessens, E.; Raj, N.; Yadav, S.; Balakrishnan, S.; Zhang, Q.; Georgiev, P.; Basak, B.; Pasricha, R.; et al. Phospholipase D activity couples plasma membrane endocytosis with retromer dependent recycling. Elife 2016, 5, e18515. [CrossRef] [PubMed]

64. Raghu, P.; Usher, K.; Jonas, S.; Chyb, S.; Polyanovsky, A.; Hardie, R.C. Constitutive activity of the light-sensitive channels TRP and TRPL in the Drosophila diacylglycerol kinase mutant, rdgA. Neuron 2000, 26, 169-179. [CrossRef]

65. Hardie, R.C. Regulation of trp channels via lipid second messengers. Annu. Rev. Physiol 2003, 65, 735-759. [CrossRef] [PubMed]

66. Storch, U.; Mederos Y Schnitzler, M.; Gudermann, T. A greasy business: Identification of a diacylglycerol binding site in human TRPC5 channels by cryo-EM. Cell Calcium 2021, 97, 102414. [CrossRef]

67. Song, K.; Wei, M.; Guo, W.; Quan, L.; Kang, Y.; Wu, J.X.; Chen, L. Structural basis for human TRPC5 channel inhibition by two distinct inhibitors. Elife 2021, 10, e63429. [CrossRef]

68. Agam, K.; von-Campenhausen, M.; Levy, S.; Ben-Ami, H.C.; Cook, B.; Kirschfeld, K.; Minke, B. Metabolic stress reversibly activates the Drosophila light-sensitive channels TRP and TRPL in vivo. J. Neurosci. 2000, 20, 5748-5755. [CrossRef] [PubMed]

69. Hardie, R.C.; Martin, F.; Chyb, S.; Raghu, P. Rescue of light responses in the Drosophila "null1" phospholipase C mutant, norpAP24 by diacylglycerol kinase mutant, rdgA and by metabolic inhibition. J. Biol. Chem. 2003, 278, 18851-18858. [CrossRef]

70. Hardie, R.C.; Gu, Y.; Martin, F.; Sweeney, S.T.; Raghu, P. In vivo light-induced and basal phospholipase C activity in Drosophila photoreceptors measured with genetically targeted phosphatidylinositol 4,5-bisphosphate-sensitive ion channels (Kir2.1). J. Biol. Chem. 2004, 279, 47773-47782. [CrossRef]

71. Hardie, R.C.; Minke, B. Spontaneous activation of light-sensitive channels in Drosophila photoreceptors. J. Gen. Physiol. 1994, 103, 389-407. [CrossRef]

72. Chu, B.; Liu, C.H.; Sengupta, S.; Gupta, A.; Raghu, P.; Hardie, R.C. Common mechanisms regulating dark noise and quantum bump amplification in Drosophila photoreceptors. J. Neurophysiol. 2013, 109, 2044-2055. [CrossRef]

73. Lev, S.; Katz, B.; Tzarfaty, V.; Minke, B. Signal-dependent hydrolysis of phosphatidylinositol 4,5-bisphosphate without activation of phospholipase C: Implications on gating of Drosophila TRPL (transient receptor potential-like) channel. J. Biol. Chem. 2012, 287, 1436-1447. [CrossRef] [PubMed]

74. Delgado, R.; Muñoz, Y.; Peña-Cortés, H.; Giavalisco, P.; Bacigalupo, J. Diacylglycerol activates the light-dependent channel TRP in the photosensitive microvilli of Drosophila melanogaster photoreceptors. J. Neurosci. 2014, 34, 6679-6686. [CrossRef] [PubMed] 
75. Delgado, R.; Bacigalupo, J. Unitary recordings of TRP and TRPL channels from isolated Drosophila retinal photoreceptor rhabdomeres: Activation by light and lipids. J. Neurophysiol. 2009, 101, 2372-2379. [CrossRef] [PubMed]

76. Delgado, R.; Delgado, M.G.; Bastin-Héline, L.; Glavic, A.; O’Day, P.M.; Bacigalupo, J. Light-Induced Opening of the TRP Channel in Isolated Membrane Patches Excised from Photosensitive Microvilli from Drosophila Photoreceptors. Neuroscience 2019, 396, 66-72. [CrossRef] [PubMed]

77. Chyb, S.; Raghu, P.; Hardie, R.C. Polyunsaturated fatty acids activate the Drosophila light-sensitive channels TRP and TRPL. Nature 1999, 397, 255-259. [CrossRef]

78. Parnas, M.; Katz, B.; Lev, S.; Tzarfaty, V.; Dadon, D.; Gordon-Shaag, A.; Metzner, H.; Yaka, R.; Minke, B. Membrane lipid modulations remove divalent open channel block from TRP-like and NMDA channels. J. Neurosci. 2009, 29, 2371-2383. [CrossRef]

79. Minke, B.; Cook, B. TRP channel proteins and signal transduction. Physiol. Rev. 2002, 82, 429-472. [CrossRef]

80. Xu, X.Z.S.; Li, H.S.; Guggino, W.B.; Montell, C. Coassembly of TRP and TRPL produces a distinct store-operated conductance Cell 1997, 89, 1155-1164. [CrossRef]

81. Vaca, L.; Sinkins, W.G.; Hu, Y.; Kunze, D.L.; Schilling, W.P. Activation of recombinant trp by thapsigargin in Sf9 insect cells. Am. J. Physiol. 1994, 267, C1501-C1505. [CrossRef]

82. Hu, Y.; Vaca, L.; Zhu, X.; Birnbaumer, L.; Kunze, D.L.; Schilling, W.P. Appearance of a novel Ca ${ }^{2+}$ influx pathway in Sf9 insect cells following expression of the transient receptor potential-like (trpl) protein of Drosophila. Biochem. Biophys. Res. Commun. 1994, 201, 1050-1056. [CrossRef]

83. Yagodin, S.; Hardie, R.C.; Lansdell, S.J.; Millar, N.S.; Mason, W.T.; Sattelle, D.B. Thapsigargin and receptor-mediated activation of Drosophila TRPL channels stably expressed in a Drosophila S2 cell line. Cell Calcium 1998, 23, 219-228. [CrossRef]

84. Hardie, R.C.; Reuss, H.; Lansdell, S.J.; Millar, N.S. Functional equivalence of native light-sensitive channels in the Drosophila trp 301 mutant and TRPL cation channels expressed in a stably transfected Drosophila cell line. Cell Calcium 1997, 21, 431-440. [CrossRef]

85. Parnas, M.; Katz, B.; Minke, B. Open channel block by $\mathrm{Ca}^{2+}$ underlies the voltage dependence of Drosophila TRPL channel. J. Gen. Physiol. 2007, 129, 17-28. [CrossRef]

86. Estacion, M.; Sinkins, W.G.; Schilling, W.P. Regulation of Drosophila transient receptor potential-like (TrpL) channels by phospholipase C-dependent mechanisms. J. Physiol. 2001, 530, 1-19. [CrossRef] [PubMed]

87. Harteneck, C.; Obukhov, A.G.; Zobel, A.; Kalkbrenner, F.; Schultz, G. The Drosophila cation channel trpl expressed in insect Sf9 cells is stimulated by agonists of G-protein-coupled receptors. FEBS Lett. 1995, 358, 297-300. [CrossRef]

88. Hambrecht, J.; Zimmer, S.; Flockerzi, V.; Cavalie, A. Single-channel currents through transient-receptor-potential-like (TRPL) channels. Pflugers Arch. 2000, 440, 418-426. [CrossRef]

89. Lev, S.; Katz, B.; Minke, B. The activity of the TRP-like channel depends on its expression system. Channels (Austin) 2012, 6, 86-93. [CrossRef]

90. Grimm, C.; Kraft, R.; Sauerbruch, S.; Schultz, G.; Harteneck, C. Molecular and functional characterization of the melastatin-related cation channel TRPM3. J. Biol. Chem. 2003, 278, 21493-21501. [CrossRef]

91. Leung, H.T.; Tseng-Crank, J.; Kim, E.; Mahapatra, C.; Shino, S.; Zhou, Y.; An, L.; Doerge, R.W.; Pak, W.L. DAG lipase activity is necessary for TRP channel regulation in Drosophila photoreceptors. Neuron 2008, 58, 884-896. [CrossRef]

92. Lundbaek, J.A.; Collingwood, S.A.; Ingólfsson, H.I.; Kapoor, R.; Andersen, O.S. Lipid bilayer regulation of membrane protein function: Gramicidin channels as molecular force probes. J. R. Soc. Interface 2010, 7, 373-395. [CrossRef]

93. Hamill, O.P. Twenty odd years of stretch-sensitive channels. Pflugers Arch. 2006, 453, 333-351. [CrossRef]

94. Spassova, M.A.; Hewavitharana, T.; Xu, W.; Soboloff, J.; Gill, D.L. A common mechanism underlies stretch activation and receptor activation of TRPC6 channels. Proc. Natl. Acad. Sci. USA 2006, 103, 16586-16591. [CrossRef] [PubMed]

95. Hardie, R.C.; Franze, K. Photomechanical responses in Drosophila photoreceptors. Science 2012, 338, 260-263. [CrossRef] [PubMed]

96. Simons, K.; Toomre, D. Lipid rafts and signal transduction. Nat. Rev. Mol. Cell Biol. 2000, 1, 31-39. [CrossRef] [PubMed]

97. Morenilla-Palao, C.; Pertusa, M.; Meseguer, V.; Cabedo, H.; Viana, F. Lipid raft segregation modulates TRPM8 channel activity. J. Biol. Chem. 2009, 284, 9215-9224. [CrossRef] [PubMed]

98. Wu, W.; Wang, Y.; Deng, X.L.; Sun, H.Y.; Li, G.R. Cholesterol down-regulates BK channels stably expressed in HEK 293 cells. PLoS ONE 2013, 8, e79952. [CrossRef]

99. Romanenko, V.G.; Fang, Y.; Byfield, F.; Travis, A.J.; Vandenberg, C.A.; Rothblat, G.H.; Levitan, I. Cholesterol sensitivity and lipid raft targeting of Kir2.1 channels. Biophys. J. 2004, 87, 3850-3861. [CrossRef]

100. Shieh, B.H.; Niemeyer, B. A novel protein encoded by the InaD gene regulates recovery of visual transduction in Drosophila. Neuron 1995, 14, 201-210. [CrossRef]

101. Tsunoda, S.; Sierralta, J.; Sun, Y.; Bodner, R.; Suzuki, E.; Becker, A.; Socolich, M.; Zuker, C.S. A multivalent PDZ-domain protein assembles signalling complexes in a G-protein-coupled cascade. Nature 1997, 388, 243-249. [CrossRef]

102. Sanxaridis, P.D.; Cronin, M.A.; Rawat, S.S.; Waro, G.; Acharya, U.; Tsunoda, S. Light-induced recruitment of INAD-signaling complexes to detergent-resistant lipid rafts in Drosophila photoreceptors. Mol. Cell. Neurosci. 2007, 36, 36-46. [CrossRef]

103. Clark, A.J.; Block, K. The absence of sterol synthesis in insects. J. Biol. Chem. 1959, 234, 2578-2582. [CrossRef]

104. Bos, M.; Burnet, B.; Farrow, R.; Woods, R.A. Development of Drosophila on sterol mutants of the yeast Saccharomyces cerevisiae. Genet. Res. 1976, 28, 163-176. [CrossRef] [PubMed] 
105. Phillips, S.E.; Woodruff, E.A.; Liang, P.; Patten, M.; Broadie, K. Neuronal loss of Drosophila NPC1a causes cholesterol aggregation and age-progressive neurodegeneration. J. Neurosci. 2008, 28, 6569-6582. [CrossRef] [PubMed]

106. Davis, M.E.; Brewster, M.E. Cyclodextrin-based pharmaceutics: Past, present and future. Nat. Rev. Drug Discov. 2004, 3, 1023-1035. [CrossRef] [PubMed]

107. Ohtani, Y.; Irie, T.; Uekama, K.; Fukunaga, K.; Pitha, J. Differential effects of alpha-, beta- and gamma-cyclodextrins on human erythrocytes. Eur. J. Biochem. 1989, 186, 17-22. [CrossRef]

108. Levitan, I.; Christian, A.E.; Tulenko, T.N.; Rothblat, G.H. Membrane cholesterol content modulates activation of volume-regulated anion current in bovine endothelial cells. J. Gen. Physiol. 2000, 115, 405-416. [CrossRef]

109. Christian, A.E.; Haynes, M.P.; Phillips, M.C.; Rothblat, G.H. Use of cyclodextrins for manipulating cellular cholesterol content. J. Lipid Res. 1997, 38, 2264-2272. [CrossRef]

110. Kilsdonk, E.P.; Yancey, P.G.; Stoudt, G.W.; Bangerter, F.W.; Johnson, W.J.; Phillips, M.C.; Rothblat, G.H. Cellular cholesterol efflux mediated by cyclodextrins. J. Biol. Chem. 1995, 270, 17250-17256. [CrossRef]

111. Matthews, D.A.; Bolin, J.T.; Burridge, J.M.; Filman, D.J.; Volz, K.W.; Kaufman, B.T.; Beddell, C.R.; Champness, J.N.; Stammers, D.K.; Kraut, J. Refined crystal structures of Escherichia coli and chicken liver dihydrofolate reductase containing bound trimethoprim. J. Biol. Chem. 1985, 260, 381-391. [CrossRef]

112. Niu, S.L.; Mitchell, D.C.; Litman, B.J. Manipulation of cholesterol levels in rod disk membranes by methyl-beta-cyclodextrin: Effects on receptor activation. J. Biol. Chem. 2002, 277, 20139-20145. [CrossRef]

113. Kabouridis, P.S.; Janzen, J.; Magee, A.L.; Ley, S.C. Cholesterol depletion disrupts lipid rafts and modulates the activity of multiple signaling pathways in T lymphocytes. Eur. J. Immunol. 2000, 30, 954-963. [CrossRef]

114. Predescu, S.A.; Predescu, D.N.; Shimizu, K.; Klein, I.K.; Malik, A.B. Cholesterol-dependent syntaxin-4 and SNAP-23 clustering regulates caveolar fusion with the endothelial plasma membrane. J. Biol. Chem. 2005, 280, 37130-37138. [CrossRef]

115. Scheiffele, P.; Roth, M.G.; Simons, K. Interaction of influenza virus haemagglutinin with sphingolipid-cholesterol membrane domains via its transmembrane domain. EMBO J. 1997, 16, 5501-5508. [CrossRef]

116. Harder, T.; Scheiffele, P.; Verkade, P.; Simons, K. Lipid domain structure of the plasma membrane revealed by patching of membrane components. J. Cell Biol. 1998, 141, 929-942. [CrossRef] [PubMed]

117. Rouquette-Jazdanian, A.K.; Pelassy, C.; Breittmayer, J.P.; Aussel, C. Revaluation of the role of cholesterol in stabilizing rafts implicated in T cell receptor signaling. Cell Signal. 2006, 18, 105-122. [CrossRef] [PubMed]

118. Gaus, K.; Rodriguez, M.; Ruberu, K.R.; Gelissen, I.; Sloane, T.M.; Kritharides, L.; Jessup, W. Domain-specific lipid distribution in macrophage plasma membranes. J. Lipid Res. 2005, 46, 1526-1538. [CrossRef] [PubMed]

119. Ottico, E.; Prinetti, A.; Prioni, S.; Giannotta, C.; Basso, L.; Chigorno, V.; Sonnino, S. Dynamics of membrane lipid domains in neuronal cells differentiated in culture. J. Lipid Res. 2003, 44, 2142-2151. [CrossRef]

120. Tikku, S.; Epshtein, Y.; Collins, H.; Travis, A.J.; Rothblat, G.H.; Levitan, I. Relationship between Kir2.1/Kir2.3 activity and their distributions between cholesterol-rich and cholesterol-poor membrane domains. Am. J. Physiol. Cell Physiol. 2007, 293, C440-C450. [CrossRef]

121. Peters, M.; Katz, B.; Lev, S.; Zaguri, R.; Gutorov, R.; Minke, B. Depletion of Membrane Cholesterol Suppresses Drosophila Transient Receptor Potential-Like (TRPL) Channel Activity. Curr. Top. Membr. 2017, 80, 233-254. [CrossRef]

122. Yancey, P.G.; Rodrigueza, W.V.; Kilsdonk, E.P.; Stoudt, G.W.; Johnson, W.J.; Phillips, M.C.; Rothblat, G.H. Cellular cholesterol efflux mediated by cyclodextrins. Demonstration Of kinetic pools and mechanism of efflux. J. Biol. Chem. 1996, 271, 16026-16034. [CrossRef]

123. Picazo-Juárez, G.; Romero-Suárez, S.; Nieto-Posadas, A.; Llorente, I.; Jara-Oseguera, A.; Briggs, M.; McIntosh, T.J.; Simon, S.A.; Ladrón-de-Guevara, E.; Islas, L.D.; et al. Identification of a binding motif in the S5 helix that confers cholesterol sensitivity to the TRPV1 ion channel. J. Biol. Chem. 2011, 286, 24966-24976. [CrossRef] [PubMed]

124. Balajthy, A.; Hajdu, P.; Panyi, G.; Varga, Z. Sterol Regulation of Voltage-Gated K. Curr. Top. Membr. 2017, 80, 255-292. [CrossRef] [PubMed]

125. Lichtenegger, M.; Tiapko, O.; Svobodova, B.; Stockner, T.; Glasnov, T.N.; Schreibmayer, W.; Platzer, D.; de la Cruz, G.G.; Krenn, S.; Schober, R.; et al. An optically controlled probe identifies lipid-gating fenestrations within the TRPC3 channel. Nat. Chem. Biol. 2018, 14, 396-404. [CrossRef] [PubMed] 